\section{CHEST}

Department of Thoracic Surgery, Cologne-Merheim Hospital, Kliniken der Stadt Köln gGmbH, Witten-Herdecke University Hospital, Cologne, Germany

${ }^{2}$ Department of Pathology, Cologne-Merheim Hospital, Kliniken der Stadt Köln gGmbH, Witten-Herdecke University Hospital, Cologne, Germany

${ }^{3}$ Department of Pneumology, Cologne-Merheim Hospital, Kliniken der Stadt Köln gGmbH, Witten-Herdecke University Hospital, Cologne, Germany

Correspondence to Dr Alberto Lopez-Pastorini, Department of Thoracic Surgery, Cologne-Merheim Hospital, Kliniken der Stadt Köln gGmbH, Witten-Herdecke University Hospital,

Ostmerheimerstr. 200, Cologne D-51109, Germany; alberto.lopez@uni-wh.de

Received 25 August 2015 Accepted 3 September 2015 Published Online First 18 September 2015
CrossMark

To cite: Lopez-Pastorini $A$, Koryllos A, Brockmann M, et al. Thorax 2016;71:199200

\title{
Pseudoaneurysm of the pulmonary artery with massive haemoptysis due to an invasive pulmonary mucormycosis
}

Alberto Lopez-Pastorini, ${ }^{1}$ Aris Koryllos, ${ }^{1}$ Michael Brockmann ${ }_{1}{ }^{2}$ Wolfram Windisch, ${ }^{3}$ Erich Stoelben ${ }^{1}$

A 62-year-old man diagnosed with glioblastoma multiforme and currently under chemoradiation therapy presented with massive haemoptysis. Chest computed tomographic scan disclosed a roundshaped formation in the right upper lobe with contrast agent leakage indicating active bleeding (figure 1). Pathological examination after right upper lobectomy revealed a pseudoaneurysm of the pulmonary artery caused by invasive mucormycosis (figure 2).

After candidiasis and aspergillosis, mucormycosis is the third most frequent invasive mycosis in immunocompromised patients. In $25 \%$ the lungs are the main site of manifestation and in these cases a high mortality is reported. ${ }^{1}$ An interesting characteristic of Mucorales species is the angioinvasion which leads to rupture of vessels with massive haemorrhage. $^{2}$
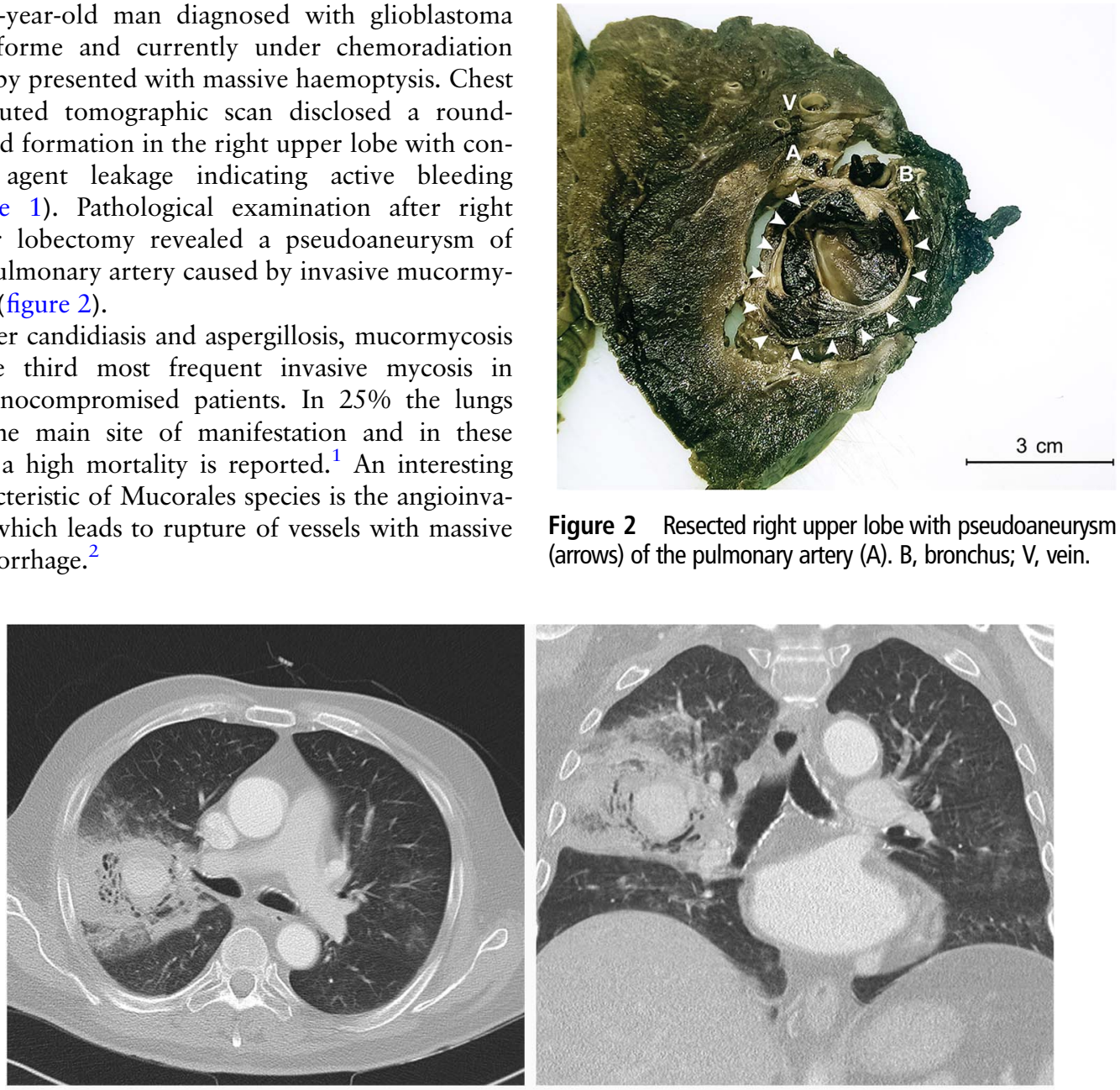

Figure 2 Resected right upper lobe with pseudoaneurysm (arrows) of the pulmonary artery (A). B, bronchus; $\mathrm{V}$, vein.
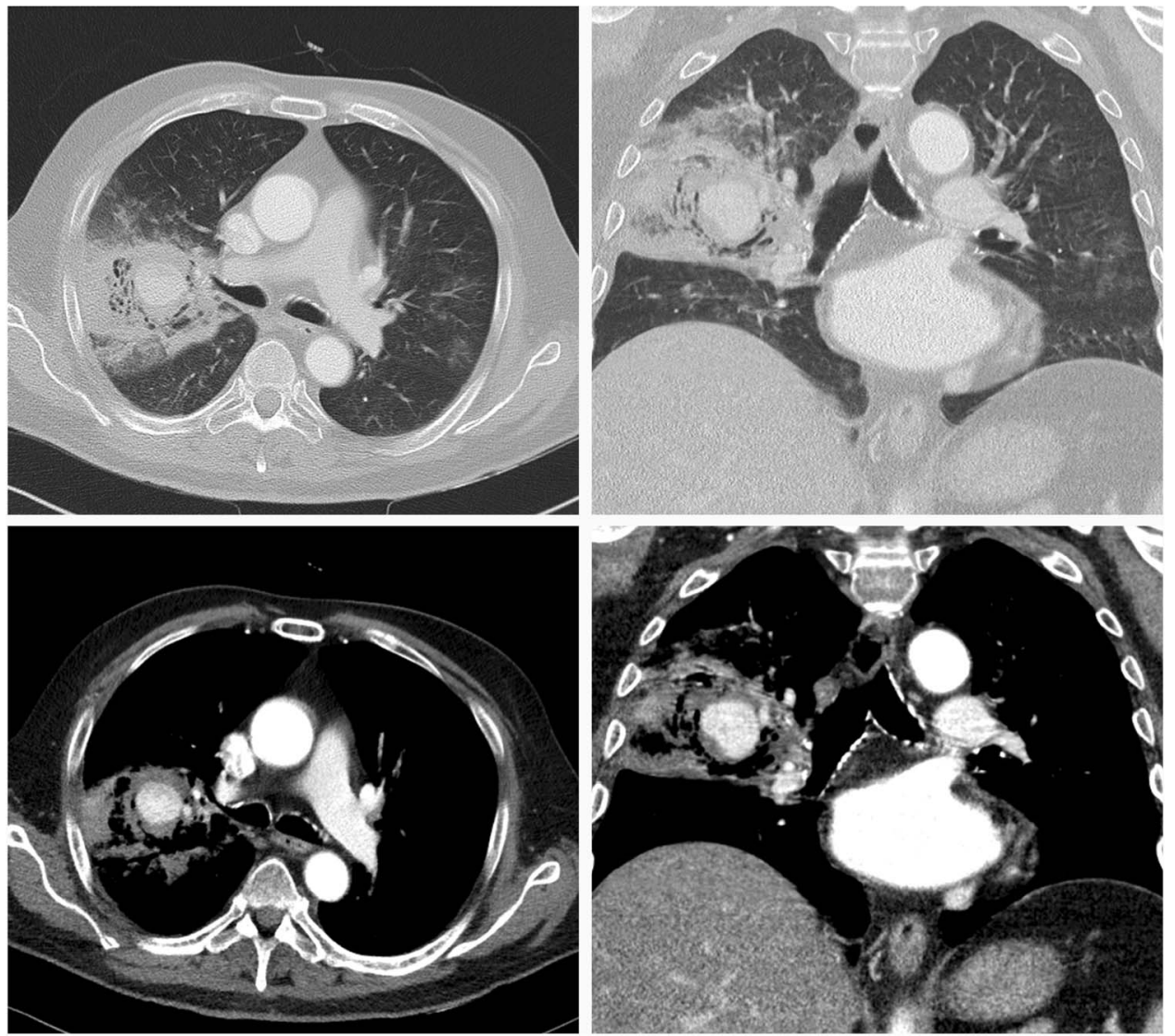

Figure 1 Contrast-enhanced computed tomography of the chest showing the pseudoaneurysm of the right upper lobe pulmonary artery. Image also demonstrates a contrast agent leakage indicating an active bleeding. 


\section{Chest clinic}

Competing interests None declared.

Patient consent Obtained.

Provenance and peer review Not commissioned; internally peer reviewed.

\section{REFERENCES}

1 Bouza E, Munoz P, Guinea J. Mucormycosis: an emerging disease? Clin Microbiol Infec 2006;12:7-23.

2 Lee FY, Mossad SB, Adal KA. Pulmonary mucormycosis: the last 30 years. Arch Intern Med 1999;159:1301-9.

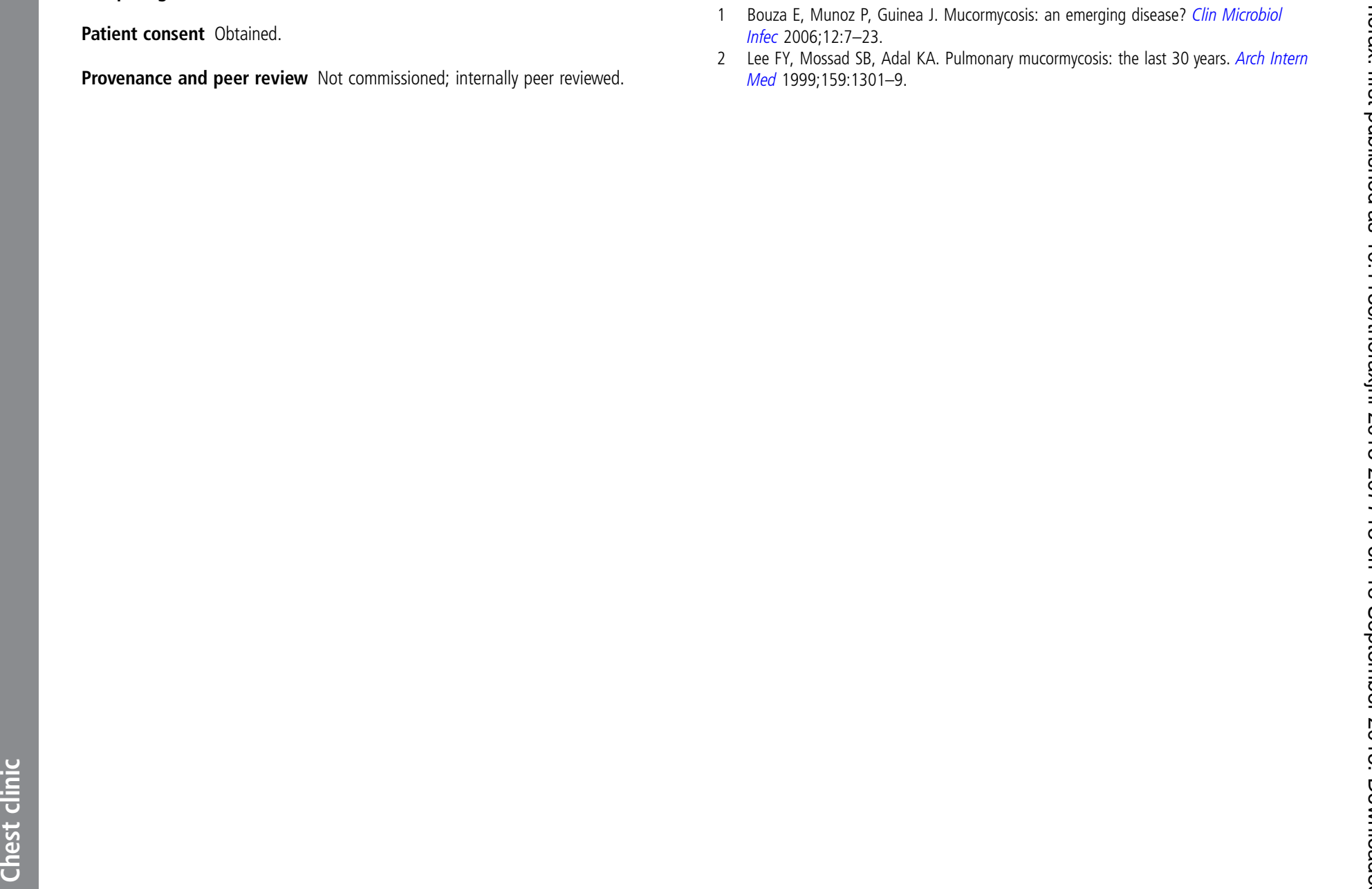

